\title{
DIFERENTES SUBSTRATOS EAMBIENTES PARA ENRAIZAMENTO DE MINI-IXORA (Ixora coccinea 'COMPACTA')
}

\author{
Different substrates and environments for mini-ixora \\ (Ixora coccinea 'Compacta') rooting
}

\author{
Elka Fabiana Aparecida Almeida ${ }^{1}$, Petterson Baptista da Luz ${ }^{2}$, Marília Andrade Lessa ${ }^{3}$, \\ Patrícia Duarte de Oliveira Paiva ${ }^{4}$, Carlos Juliano Brant Albuquerque ${ }^{5}$, Marcus Vanner Carvalho de Oliveira ${ }^{6}$
}

\begin{abstract}
RESUMO
A mini-ixora (Ixora coccinea 'Compacta') é uma espécie muito apreciada para uso em paisagismo, especialmente em jardins tropicais. A propagação é feita por estaquia, no entanto, a porcentagem de enraizamento é bastante baixa. Sendo assim, objetivou-se com este trabalho avaliar substratos e ambientes para o enraizamento da mini-ixora. Foram utilizadas estacas apicais com comprimento de $10 \mathrm{~cm}$, as quais foram cultivadas em dois tipos de substratos: areia e o produto comercial Plantmax ${ }^{\circledR}$. Utilizaram-se também três ambientes de enraizamento: câmara úmida, estufa e enraizador tradicional (telado com $50 \%$ de sombreamento). O delineamento experimental utilizado foi o de parcelas subdivididas, sendo três ambientes nas parcelas e dois substratos nas subparcelas. Utilizaramse 5 repetições e 10 estacas por parcela. Analisando-se todos os resultados 100 dias após a implantação do experimento, observouse que a areia proporcionou maior porcentagem de enraizamento (68\%) quando comparada ao Plantmax (48\%). A câmara úmida também foi o ambiente que proporcionou melhores condições para a propagação da mini-ixora com maior porcentagem de enraizamento, $98 \%$, em relação a estufa (66\%) e ao enraizador tradicional (10\%). A areia e a câmara úmida também favoreceram a formação de raízes de melhor qualidade. Concluiu-se que o melhor substrato para propagação da mini-ixora foi areia devendo as estacas serem dispostas em câmara úmida.
\end{abstract}

Termos para indexação: Propagação, planta ornamental, estacas apicais, mini-ixora.

\begin{abstract}
The mini-ixora (Ixora coccinea 'Compacta') is a species highly appreciated for use in tropical gardens. Its propagation is made by cutting, however, its rooting percentage is very low so, the aim of this work was to evaluate substrates and environments for the mini-ixora rooting. Apical cuttings with $10 \mathrm{~cm}$ of length were used in two substrates: sand and Plantmax ${ }^{\circledR}$. Three rooting environments were used: wet chamber, greenhouse and conventional rooting (shade cloth with $50 \%$ of shade). The experiment was carried out by using split plots with three different environments in the main plot and two substrates in the subplots. One also used five replications and ten cuttings per plot. Analyzing the results one hundred days after the experiment implantation one noticed that the sand had proportioned higher percentage of rooting (68\%) compared to Plantmax (48\%). The wet chamber also was the environment that provided better conditions for the propagation of the mini-ixora, with the highest percentage of rooting, $98 \%$, compared to the greenhouse, $66 \%$ and to the conventional rooting, $10 \%$. Moreover, sand and wet chamber also provided a better root quality. One concluded that the best substrate for mini-ixora propagation was sand and the cuttings should be placed in the wet chamber.
\end{abstract}

Index terms: Propagation, ornamental plant, apical cuttings, mini-ixora.

(Recebido em 22 de novembro de 2005 e aprovado em 2 de abril de 2007)

\section{INTRODUÇÃO}

A mini-ixora (Ixora coccinea 'Compacta') é um arbusto semi-herbáceo, ereto e ramificado, originário da Malásia, atingindo de 0,40 a $0,80 \mathrm{~cm}$ de altura, com florescimento atrativo, sendo muito utilizada no paisagismo, especialmente em jardins tropicais. Há variedades diferentes com inflorescências em tons vermelho-alaranjado, amarelo e rosa (LORENZI \& SOUZA, 2001).

'Doutora, Pesquisadora - Centro Tecnológico do Sul de Minas/CTSM - Fazenda Experimental Risoleta Neves/FERN - Empresa de Pesquisa Agropecuária de Minas Gerais/EPAMIG - Br 494, Km 2 - Colônia do Bengo - 36301-360 - São João Del Rei, MG - elka@epamig.br

${ }^{2}$ Mestre, Professor - Departamento de Agronomia - Universidade do Estado de Mato Grosso/UNEMAT - Avenida Tancredo Neves, 1095 - Cavalhada 2 78200-000 - Cárceres, MT - petterbaptista@yahoo.com.br

${ }^{3}$ Doutoranda - Departamento de Agricultura/DAG - Universidade Federal de Lavras/UFLA - Cx. P. 3037 - $37200-000$ - Lavras, MG marilialessa@terra.com.br

${ }^{4}$ Doutora, Professora - Departamento de Agricultura/DAG - Universidade Federal de Lavras/UFLA - Cx. P. 3037 - $37200-000$ - Lavras, MG pdolivei@ufla.br

${ }^{5}$ Mestre, Pesquisador - Centro Tecnológico do Norte de Minas/CTNM - Empresa de Pesquisa Agropecuária de Minas Gerais/EPAMIG - Cx. P. 12 39525-000 - Nova Porteirinha, MG - carlosjuliano@epamig.br

${ }^{6}$ Doutorando - Departamento de Agricultura/DAG - Universidade Federal de Lavras/UFLA - Cx. P. 3037 - $37200-000$ - Lavras, MG marcus_vanner@hotmail.com 
A multiplicação é feita por estaquia (LORENZI \& SOUZA, 2001), no entanto, os viveiristas têm observado uma porcentagem de enraizamento bastante baixa.

Conforme Albuquerque \& Albuquerque (1982), o potencial de enraizamento, bem como a qualidade e a quantidade de raízes nas estacas, podem variar com a espécie, cultivar, condições ambientais (fatores externos) e condições internas da própria planta.

Segundo Avery \& Beyl (1991) o uso de algumas tecnologias pode melhorar tanto a qualidade da muda quanto a porcentagem de enraizamento e qualidade das estacas enraizadas. Dentre estas, pode-se citar o uso de substratos mais adequados para proporcionarem maior enraizamento, melhor distribuição e conformação das raízes (KLEIN et al., 2000).

De acordo com Hoffmann et al. (1996), o substrato destina-se a sustentar as estacas durante o período de enraizamento, mantendo sua base em ambiente úmido, escuro e suficientemente aeróbio.

No processo de propagação por estaquia, diversas são as opções de tipos de substratos. Segundo Kämpf (2000), os mais comuns observados nos viveiros de produção de mudas são areia, casca de arroz carbonizada, vermiculita, solo e a mistura destes.

A utilização de areia como substrato é vantajosa, pois possui baixo custo, é de fácil disponibilidade e apresenta características positivas quanto à drenagem, sendo seu uso adequado para enraizamento de estacas herbáceas e semi-lenhosas (FACHINELLO et al., 1994).

Além da utilização de um substrato adequado, para as estacas de difícil enraizamento é preciso se observar o ambiente em que as mesmas são dispostas para enraizar. Recomenda-se a nebulização intermitente, que mantém sobre as folhas uma película de água que tende a reduzir a temperatura do ar e a taxa de transpiração. Recomenda-se também a manutenção das estacas em locais com luminosidade mediana em temperatura ambiente entre 15$25^{\circ} \mathrm{C}$. Tem-se utilizado ripados ou coberturas de polietileno e câmaras total ou parcialmente fechadas (HARTMANN et al., 1990; ONO \& RODRIGUES, 1996).

Considerando a importância que a mini-ixora representa para o paisagismo, objetivou-se com este trabalho identificar o melhor substrato e ambiente para o enraizamento desta espécie.

\section{MATERIAL E MÉTODOS}

O experimento foi realizado no Viveiro de Plantas Ornamentais do Departamento de Agricultura da
Universidade Federal de Lavras - MG que está localizada no município de Lavras, coordenadas geográficas $21^{\circ} 14^{\prime}$ 30 " S e $45^{\circ} 00^{\prime} 10^{\prime \prime} \mathrm{W}$, a uma altitude de 918 m e precipitação média anual de 1.529,7 mm (BRASIL, 1992).

Para indução de enraizamento, foram avaliados dois tipos de substratos (Plantmax ${ }^{\circledR}$ Hortaliças e areia) em três ambientes de enraizamento: a) estufa com nebulização intermitente, b) enraizador tradicional de estrutura coberta com plástico de polietileno e telado sombrite $50 \%$ sendo a irrigação por microaspersão, c) câmara úmida, que consistia em caixa de amianto, coberta com plástico polietileno transparente mantido sob telado sombrite $50 \%$.

Estacas apicais de mini-ixora (Ixora coccinea 'Compacta') foram colhidas de plantas matrizes localizadas no campus da UFLA e padronizadas pelo tamanho $(10 \mathrm{~cm})$. As estacas foram dispostas em bandejas de poliestireno expandido da Tecnocell ${ }^{\circledR}$ com $11 \mathrm{~cm}$ de altura composta por 72 células de $110 \mathrm{~cm}^{3}$ cada uma.

O delineamento experimental utilizado foi o de parcelas subdivididas, sendo três (3) ambientes nas parcelas e dois (2) substratos nas subparcelas. Utilizaramse 5 repetições e 10 estacas por parcela.

As avaliações foram realizadas 100 dias após a implantação do experimento, observando-se o percentual de enraizamento, comprimento das raízes e a qualidade das mesmas, sendo este último critério realizado a partir de notas atribuídas por uma banca de 2 avaliadores. Atribuiuse nota 1 para estacas com poucas raízes, 2 para estacas com uma quantidade média de raízes e 3 para estacas com muitas raízes (Figura 1).

Os dados foram interpretados por meio de análise de variância e as médias foram comparadas utilizando-se o teste de Tukey a 5\% de probabilidade, através do software SISVAR (Sistema de Análise de Variância para Dados Balanceados) (FERREIRA, 2000).

\section{RESULTADOS E DISCUSSÃO}

Não se observou interação entre os substratos testados e os ambientes nos quais as estacas foram dispostas para o enraizamento para todas as características analisadas. No entanto, houve diferença significativa entre os diferentes ambientes e entre os diferentes substratos testados. Observou-se que a câmara úmida proporcionou o enraizamento em $98 \%$ das estacas. Comparando-se com os demais tratamentos, constatou-se que as estacas dispostas na estufa de nebulização intermitente apresentaram $66 \%$ de enraizamento e no enraizador tradicional (comumente utilizado pelos viveiristas) somente $10 \%$ das estacas enraizaram (Figura 2A). 


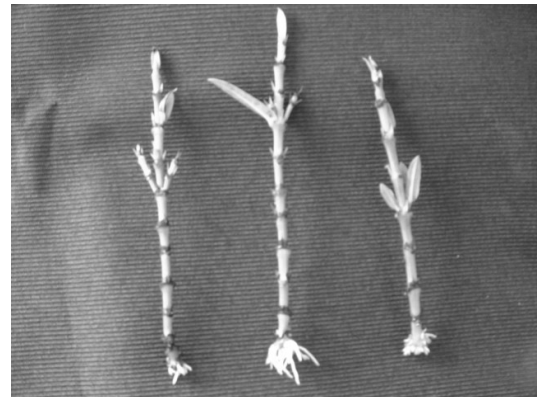

Nota 1

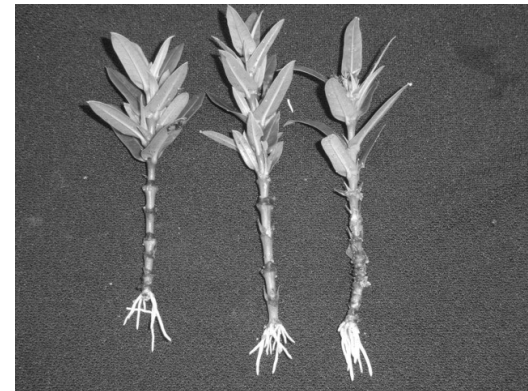

Nota 2

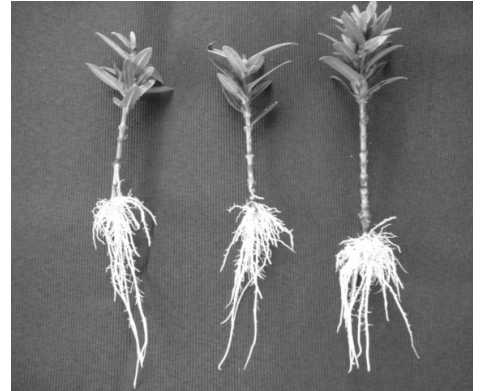

Nota 3

Figura 1 - Notas atribuídas (por uma banca de dois avaliadores) de acordo com o desenvolvimento das raízes de miniixora. UFLA, Lavras, MG, 2004.

Fachinello et al. (1994) afirmam que a utilização da nebulização intermitente permite a redução da perda de umidade pela formação de uma película de água sobre as folhas, além da diminuição da temperatura. As estacas dispostas em câmara úmida apresentaram resultados superiores às estacas dispostas na estufa de nebulização, indicando ser essa estrutura bastante eficiente para propagação de mini-ixora.

A porcentagem de enraizamento também foi influenciada pelo substrato (Figura 2B). As estacas dispostas na areia apresentaram $68 \%$ de enraizamento. Ao contrário, quando cultivadas em Plantmax ${ }^{\circledR}, 48 \%$ apresentaram enraizamento.

Entre os ambientes estudados, observou-se que o maior comprimento de raízes formadas ocorreu quando as estacas foram dispostas para enraizar em câmara úmida $(5,94 \mathrm{~cm})$. As estacas dispostas em estufa apresentaram $0,29 \mathrm{~cm}$ e as que permaneceram em enraizador tradicional apresentaram 0,03 cm de comprimento médio (Figura 2C).

Em relação aos substratos avaliados, verificou-se que a areia proporcionou maior comprimento das raízes por estaca, $(2,31 \mathrm{~cm})$ em comparação com o substrato Plantmax ${ }^{\circledR}$ que proporcionou apenas $1,87 \mathrm{~cm} \mathrm{de}$ comprimento (Figura 2D).

Para a característica qualidade das raízes, que corresponde ao padrão estipulado para avaliação pelo critério de notas, observou-se que dentre os ambientes testados, a câmara úmida proporcionou os melhores resultados, com nota média de 2,28. Observou-se que as estacas dispostas em estufa ou telado receberam as menores notas com relação à qualidade, ou seja, 0,71 e 0,10 respectivamente. Nessas não se observou formação de raízes vigorosas (Figura $2 \mathrm{E}$ ).

As estacas dispostas em substrato areia apresentaram melhor qualidade das raízes formadas, com nota média de 1,24 , já o substrato Plantmax ${ }^{\circledR}$ proporcionou nota média de 0,82 (Figura 2F). Estas notas foram baixas pelo fato de ser considerada a média dos três ambientes. Considerando-se apenas as estacas enraizadas na câmara úmida, a nota média da qualidade das raízes dispostas na areia foi de 2,58.

Os resultados obtidos confirmam as indicações de Fachinello et al. (1994), de que a perda de água é uma das principais causas das mortes das estacas. As estacas dispostas na câmara úmida possivelmente apresentaram os melhores resultados devido à retenção de umidade que é proporcionada neste ambiente.

A partir dos resultados foi possível observar que, em todas as características avaliadas, a utilização de areia como substrato foi mais eficiente que o Plantmax ${ }^{\circledR}$ para o enraizamento de estacas de mini-ixora. Esses resultados concordam com os resultados obtidos por Vale et al. (2006), que observaram maior porcentagem de enraizamento em estacas de goiabeira 'Paluma' quando o substrato areia foi utilizado, comparando-se ao Plantmax ${ }^{\circledR}$. Entretanto, resultados diferentes foram observados por Bona et al. (2005). Segundo esses autores o Plantmax ${ }^{\circledR}$ foi superior à areia para o enraizamento de estacas de diferentes espécies de Baccharis. Também, Pio et al. (2005) observaram maior porcentagem de enraizamento em estacas herbáceas de figueira, utilizando-se o substrato Plantmax ${ }^{\circledR}$ comparandose a casca de pinus, a vermiculita e a mistura de solo e esterco.

Segundo Fachinello et al. (1994), a utilização de areia como substrato é vantajosa, pois apresenta características positivas quanto à drenagem, sendo seu uso adequado para estacas herbáceas e semi-lenhosas. Estas recomendações podem ser confirmadas com os resultados obtidos na propagação de mini-ixora, pois apesar da maior retenção de umidade observada na câmara úmida, os 
melhores resultados foram obtidos neste ambiente quando a areia foi utilizada como substrato.

A areia apresenta alta densidade (KÄMPF, 2000), favorecendo a sustentação das estacas, característica importante para um substrato utilizado para o enraizamento. Tanto o Plantmax ${ }^{\circledR}$ quanto a areia são substratos que apresentam facilidade para drenagem de água, contudo, a areia possui essa característica de forma mais eficiente. Kämpf (2000) recomenda que o substrato utilizado para a propagação de estacas seja extremamente poroso, com baixa capacidade de retenção de água. Oliveira et al. (2001)
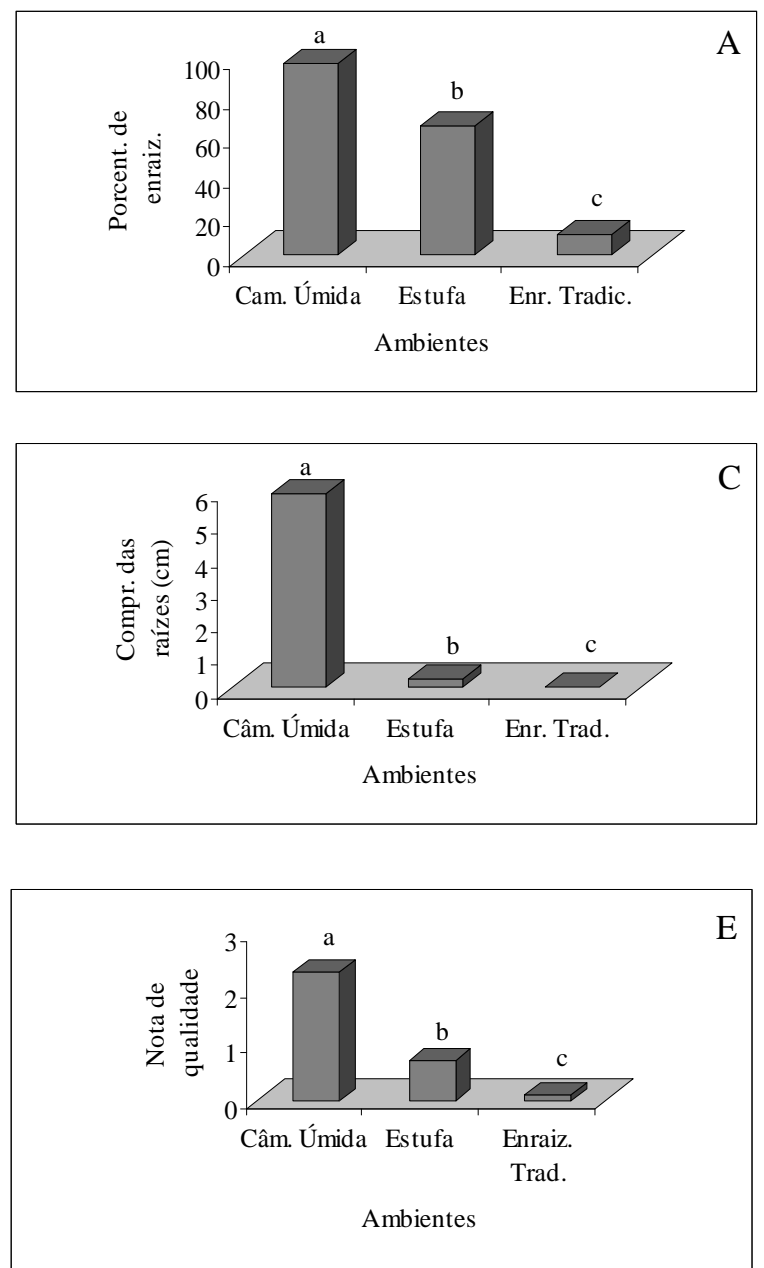

recomenda evitar o excesso de umidade nos substratos que pode favorecer o aparecimento de doenças fúngicas, afetando o enraizamento das estacas. Desta forma, podese inferir que e a maior estabilidade das estacas dispostas na areia e a característica de alta drenagem desse substrato são fatores que proporcionaram melhores condições para o enraizamento de mini-ixora, nas condições experimentais estudadas.

São necessários novos estudos para confirmarem esse resultado que foi diferente dos resultados citados por outros autores para outras espécies.
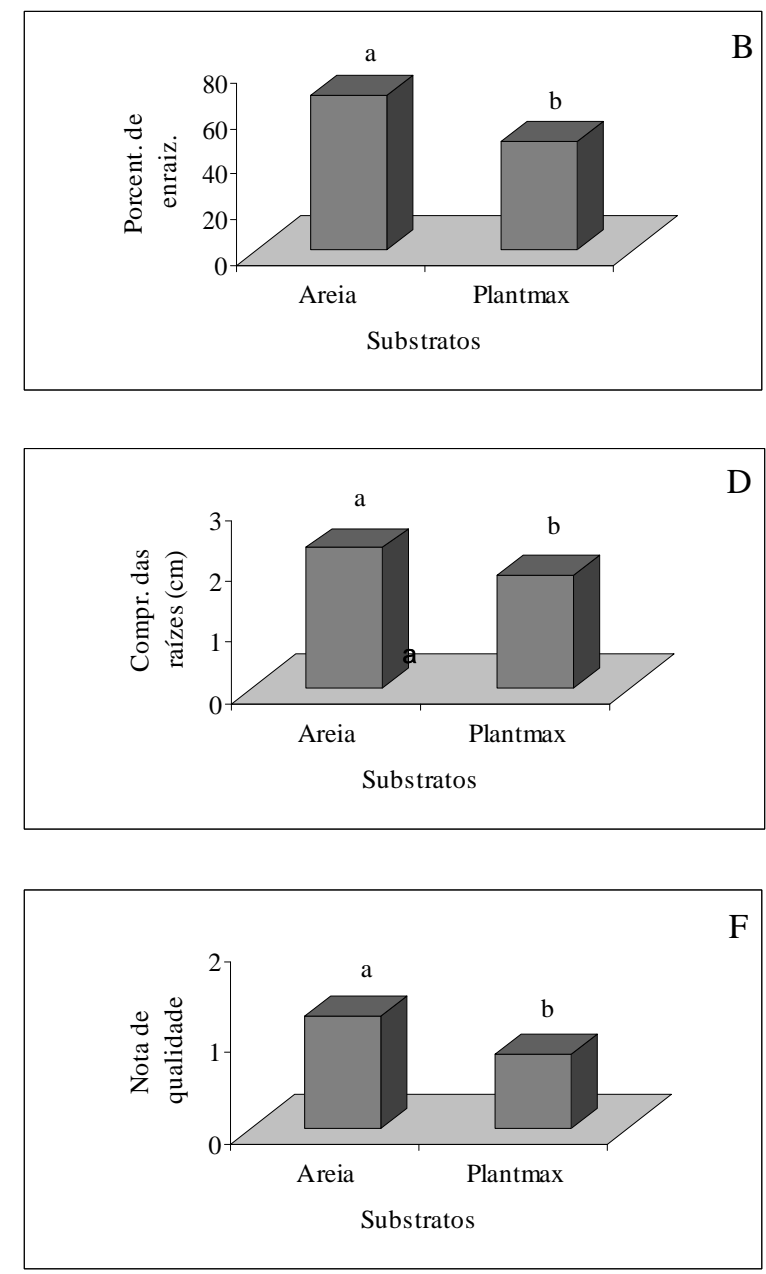

Figura 2 - Porcentagem de enraizamento de mini-ixora (Ixora coccinea 'Compacta') em função dos ambientes (A) e substratos (B) utilizados para disposição das estacas. Comprimento médio das raízes de mini-ixora (cm) em função dos ambientes (C) e substratos (D) utilizados para enraizamento. Qualidade das raízes de mini-ixora atribuída através de notas médias, em função dos ambientes (E) e substratos (F) utilizados para enraizamento. UFLA, Lavras, MG, 2004. 


\section{CONCLUSÃO}

A utilização de areia como substrato para propagação de estacas apicais de mini-ixora é eficiente devido à alta porcentagem de enraizamento e qualidade das raízes formadas.

A câmara úmida é uma estrutura simples, de baixo custo que apresenta características favoráveis para propagação da mini-ixora.

\section{AGRADECIMENTOS}

Os autores agradecem ao Dr. Alonso Lamas pelas valiosas colaborações para a realização desse trabalho.

\section{REFERÊNCIAS BIBLIOGRÁFICAS}

ALBUQUERQUE, T. E. S.; ALBUQUERQUE, J. A. S. Influência do tipo de estaca e de alguns reguladores de crescimento no enraizamento de estacas de figueira (Fícus carica L.). In: CONGRESSO BRASILEIRO DE FRUTICULTURA, 6., 1981, Recife. Anais... Recife: SBF, 1982. v. 4, p. 762-770.

AVERY, J. D.; BEYL, C. B. Propagation of peach cuttings using foam cubes. HortScience, Alexandria, v. 26, n. 9, p. 1152-1154, 1991.

BONA, C. M. de; BIASI, L. A.; NAKASHIMA, T. Estaquia de três espécies de Baccharis. Ciência Rural, Santa Maria, v. 35, n. 1, p. 223-226, jan./fev. 2005.

BRASIL. Ministério da Agricultura. Normais climatológicas: 1961-1990. Brasília, DF: Embrapa/DNMET, 1992. 84 p.

FACHINELLO, J. C.; HOFFMANN, A.; NACHTIGAL, J. C.; KERSTEN, E.; FORTES, G. R. L. Propagação de plantas frutíferas de clima temperado. Pelotas: UFPel, 1994. 179 p.

FERREIRA, D. F. Análises estatísticas por meio do SISVAR para windows versão 4.0. In: REUNIÃO ANUAL DA REGIÃO BRASILEIRA DA SOCIEDADE INTERNACIONAL DE BIOMETRIA, 45., 2000, São Carlos. Anais... São Carlos: UFSCar, 2000. p. 225-258.
HARTMANN, H. T.; KESTER, D. E.; DAVIES JUNIOR, F. T. Plant propagation: principles and practices. 5. ed. New York: Prentice Hall, 1990. 647 p.

HOFFMANN, A.; CHALFUN, N. N. J.; ANTUNES, L. E. C.; RAMOS, J. D.; PASQUAL, M.; SILVA, C. R. de R. e. Fruticultura comercial: propagação de plantas frutíferas. Lavras: UFLA/FAEPE, 1996. 319 p.

KÄMPF, A. N. Produção comercial de plantas ornamentais. Guaíba: Agropecuária, 2000. 254 p.

KLEIN, J. D.; COHEN, S.; HEBBE, U. Seasonal variation in rooting ability of myrtle (Myrtus communis L.) cutting. Scientia Horticulture, Amsterdam, v. 83, n. 1, p. 71-76, 2000.

LORENZI, H.; SOUZA, H. M. Plantas ornamentais no Brasil: arbustivas, herbáceas e trepadeiras. 3. ed. Nova Odessa: Plantarum, 2001. 1088 p.

OLIVEIRA, M. C. de; RIBEIRO, J. F.; RIOS, M. N. da; RESENDE, M. E. Enraizamento de estacas para produção de mudas de espécies nativas de matas de galeria. Brasília, DF: Embrapa, 2001. 4 p. (Recomendação técnica, 41).

ONO, E. O.; RODRIGUES, J. D. Aspectos da fisiologia do enraizamento de estacas caulinares. Jaboticabal: FUNEP, 1996. $83 \mathrm{p}$.

PIO, R.; ARAÚJO, J. P. C. de; BASTOS, D. C.; ALVES, A. S. R.; ENTELMANN, F. A.; SARPARE FILHO, J. A.; MOURÃO FILHO, F. de A. A. Substrato no enraizamento de estacas herbáceas de figueira oriundas da desbrota. Ciência e Agrotecnologia, Lavras, v. 29, n. 3, p. 604-609, maio/jun. 2005.

VALE, M. R. do; CHALFUN, N. N. J.; MENDONÇA, V.; COELHO, G. V. de A.; MIRANDA, C. S. de. Substrato no enraizamento de diferentes tipos de estacas de goiabeira cultivar 'Paluma'. Caatinga, Mossoró, v. 19, n. 1, p. 34-38, jan./mar. 2006. 